
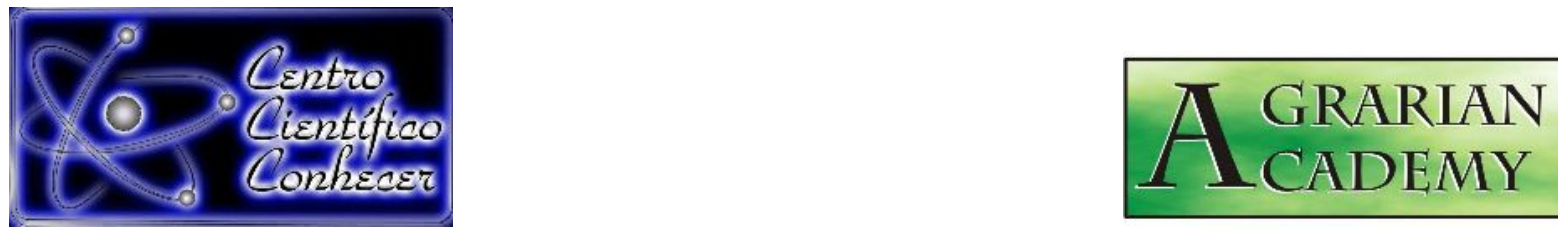

\title{
MAPEAMENTO DA EXPANSÃO AGRÍCOLA NO MUNICÍPIO DE ALTA FLORESTA, MT NO PERÍODO DE 2008 A 2015
}

Rafael Polachini ${ }^{1}$; Eder de Camargo Deluski ${ }^{2}$; Sylvia Karla Ferreira dos Santos ${ }^{2}$; Wesley Vicentino Claudino ${ }^{2}$, Edgley Pereira da Silva ${ }^{2}$

${ }^{1}$ Engenheiro agrônomo (rafaelpolachini13@hotmail.com), Alta Floresta/MT, Brasil ${ }^{2}$ Professor da Faculdade de Ciências Agrárias e Biológicas, UNEMAT, Alta Floresta/MT, Brasil.

Recebido em: 14/07/2018 - Aprovado em: 28/07/2018 - Publicado em: 31/07/2018 DOI: 10.18677/Agrarian_Academy_2018a37

\begin{abstract}
RESUMO
Considerando a escassez de informações geoespaciais sobre a expansão agrícola no município de Alta Floresta-MT, há uma crescente utilização de geotecnologias para o monitoramento e tomada de decisões sobre o uso do solo. O presente trabalho objetivou mapear a área de expansão agrícola no município de Alta Floresta-MT, entre os anos de 2008 e 2015 por meio de análise temporal de imagens de satélite. Nesse estudo, foram utilizados software Arcgis 9.3 e imagens orbitais dos satélites Spot-5 do ano de 2008, Landsat-5, ResourceSat-1 e Landsat-8, que passaram por um processo de classificação supervisionada. As classes foram interpretadas como Agricultura, Floresta, Pastagem, Espelho d' água e Solo exposto. Os dados analisados demonstraram que, ao longo do período 2008 a 2015, houve queda de $1,46 \%$ da área de floresta e consequentemente as áreas de pastagens aumentaram de 32,59\%, em 2008, para 33,85\% em 2015. Poucas áreas de agricultura foram observadas em 2008 (0,19\%). Porém, em 2015, a agricultura representa $1,03 \%$ da área total do município, desenvolvido com mais de $90 \%$ com relevo considerado plano a suave ondulado e com altitude variando entre 200 a 480 $\mathrm{m}$ demonstrando que grande parte do município é favorável à mecanização. $\mathrm{A}$ agricultura evoluiu: em 2008, a atividade ocupava 0,19\%, aumentando nos anos seguintes e chegando a $1,03 \%$ no ano de 2015 , porém ainda pouco expressiva quando comparada à área total do município. As atividades agrícolas estão se desenvolvendo principalmente em áreas com declividade inferior a $8 \%$.
\end{abstract}

PALAVRAS-CHAVE: Agricultura, Geotecnologias, Monitoramento, Planejamento.

\section{MAPPING OF AGRICULTURAL EXPANSION IN THE MUNICIPALITY OF ALTA FLORESTA, MT IN THE PERIOD 2008 TO 2015}

\section{ABSTRACT}

Considering the scarcity of geospatial information on agricultural expansion in the municipality of Alta Floresta-MT, there is an increasing use of Geotechnologies for monitoring and making decisions on land use. This study aimed to map the area of AGRARIAN ACADEMY, Centro Científico Conhecer - Goiânia, v.5, n.9; p. 3772018 
agricultural expansion in the municipality of Alta Floresta-MT, between the years 2008 and 2015 through temporal satellite images analysis. In this study were used Arcgis 9.3 software and satellite images of Spot-5 satellites from 2008, Landsat-5, ResourceSat-1 and Landsat-8, which passed by a supervised classification process. The classes were interpreted as Agriculture, Forest, Pasture, Water and Exposed Soil. The analyzed data showed that over the period 2008 to 2015 , a drop of $1.46 \%$ of the forest area and consequently the pasture areas increased from $32.59 \%$, in 2008 to 33.85\% in 2015. Few areas agriculture were observed in 2008 (0.19\%). But in 2015, agriculture accounts for $1.03 \%$ of the total area of the municipality, developed with over $90 \%$ embossed considered plan to gently rolling and altitude ranging from $200-480 \mathrm{~m}$ demonstrating that much of the municipality is favorable to mechanization. Agriculture evolved: in 2008 the activity held $0.19 \%$ increase in the following years, reaching $1.03 \%$ in 2015 , but still not very significant when compared to the total area of the municipality. Agricultural activities are developing mainly in areas with slopes less than $8 \%$.

KEYWORDS: Agriculture, Geotechnologies, Monitoring, Planning.

\section{INTRODUÇÃO}

Nas últimas décadas, houve um aumento das terras aráveis e das pastagens à custa das florestas. A expansão agrícola, para atender à demanda da população global por alimentos, intensificou o uso dos recursos naturais e a partir daí, considera-se a natureza como fonte de recursos inesgotáveis. Neste contexto, vivese num ambiente onde a natureza se faz profundamente agredida, mas, devido à preocupação com a escassez dos recursos, bem como, a degradação gerada pelas formas de produção modernas, agravaram-se os processos de destruição dos recursos naturais (LOPES et al., 2016).

A produção agropecuária vem se expandindo principalmente para o CentroOeste, o Norte e o Matopiba, como resultado da incorporação de ganhos de escala produtiva (VIEIRA-FILHO, 2016). Atualmente o Brasil se destaca como um dos maiores produtores mundiais de grãos, o crescimento da agricultura brasileira é vinculado à ocupação de novas áreas, por meio da transferência da maior parte do plantio de grãos para essas regiões (BARBOSA, 2015).

Nesse contexto, a detecção de mudanças na cobertura e uso da Terra é uma aliada para entender as transformações ocorridas pelos principais fatores antropogênicos e naturais em uma localidade e forte instrumento de planejamento. A detecção de mudança é uma das principais aplicações do Sensoriamento Remoto e dos Sistemas de Informações Geográficas (SIGs) (ROMÃO, 2014).

O uso de imagens de satélite é o melhor caminho para gerenciar e diagnosticar o comportamento e o potencial agrícola de uma região, uma vez que as informações derivadas das imagens provêm respostas rápidas e seguras e auxiliam o monitoramento e mapeamento eficiente dessas áreas. A utilidade das imagens de satélite é muito vasta e fundamental para estudar os fenômenos geográficos da superfície terrestre, uma vez que isso pode ser feito em várias escalas de análise, tanto temporal como espacial e o desenvolvimento das geotecnologias advindas do sensoriamento remoto, ou seja, das tecnologias envolvidas com a aquisição de dados espaciais, processamento e manipulação dos mesmos, armazenamento e apresentação de informações espaciais, tem se popularizado nos últimos anos como uma ferramenta de grande potencial para a interação e identificação dos elementos formadores da paisagem geográfica (CRISPIM; ALBANO, 2016).

Métodos de mapeamento da atividade agrícola que exploram a alta resolução AGRARIAN ACADEMY, Centro Científico Conhecer - Goiânia, v.5, n.9; p. 3782018 
temporal de alguns sensores têm sido propostos como uma alternativa para a geração rápida de mapas englobando extensas regiões. A abordagem espectrotemporal tem mostrado potencial de aplicação na análise da superfície terrestre, sobretudo nas áreas com elevada dinâmica espectro-temporal, como é o caso das culturas agrícolas (PINTO et al., 2013). Para a realização da técnica da análise multitemporal, encontram-se disponíveis diversos tipos de imagens geradas por sensores orbitais, que permitem monitorar 0 uso da terra, a evolução do desmatamento e o crescimento urbano (ROMÃO, 2014).

Recentemente, no município de Alta Floresta-MT, diversas áreas onde se desenvolve a pecuária estão sendo substituídas por áreas agrícolas. Neste contexto, as técnicas de Sensoriamento Remoto aliadas aos Sistemas de Informações Geográficas (SIGs) auxiliam no mapeamento dessas regiões. Considerando a escassez de informações geoespaciais sobre a expansão agrícola no município de Alta Floresta-MT e a crescente utilização de geotecnologias para o monitoramento e tomada de decisões sobre o uso do solo, o presente trabalho objetivou mapear a área de expansão e intensificação agrícola no município de Alta Floresta-MT, entre os anos de 2008 e 2015, por meio de análise temporal de imagens de satélite.

\section{MATERIAL E MÉTODOS}

\section{Localização da área de estudo}

O estudo abrangeu o Município de Alta Floresta-MT, situado no norte do estado de Mato Grosso, com coordenada geográfica central 09 52' 33" de Latitude Sul e 56 05' 09" de Longitude Oeste, correspondendo a uma área aproximadamente de $8.913,04 \mathrm{~km}^{2}$ (Figura 1).

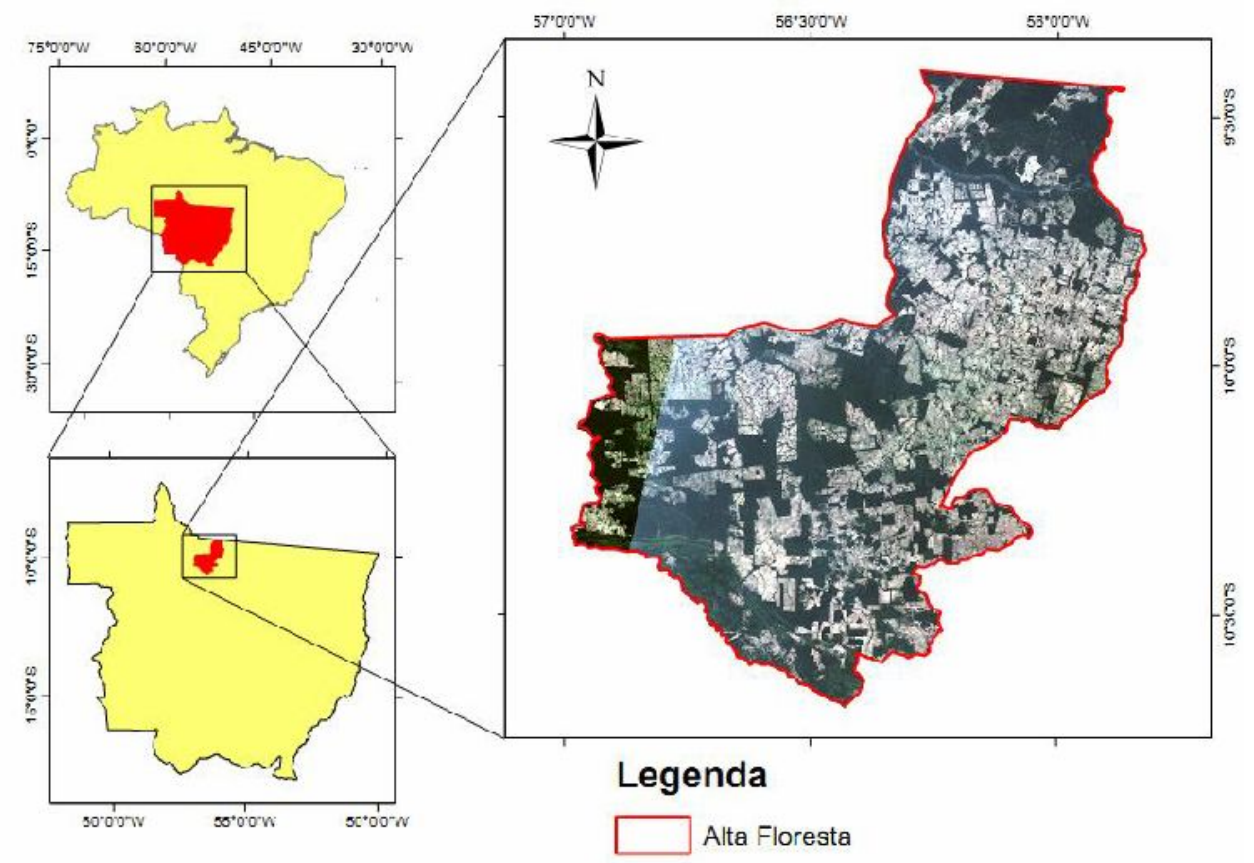

FIGURA 1 - Localização geográfica do município de Alta Floresta-MT. Alta Floresta-MT, (2015). Fonte: Os autores

O clima de Alta Floresta-MT encontra-se na zona IB3a, equatorial continental úmido com estação seca definida da depressão sul amazônica, com temperatura 
média anual entre 24,3 e $24,8^{\circ} \mathrm{C}$, com precipitação pluviométrica entre 2000 e 2300 $\mathrm{mm}$ (SEPLAN, 2006).

O município tem fitofisionomias constituídas por Floresta Ombrófila Aberta e Densa, Floresta Estacional e Cerrado. O relevo é formado pelo Planalto Apiacás Sucurundi e a Depressão Interplanáltica da Amazônia Meridional. Os solos variam de Argissolo Amarelo e Vermelho-Amarelo, com menor quantidade o Latossolo e solos Hidromórficos. Os solos possuem baixa a média fertilidade, com baixos teores de fósforo e médio teor de potássio, cálcio, magnésio e matéria orgânica (FERREIRA, 2001).

\section{Procedimentos metodológicos}

$\mathrm{Na}$ elaboração deste trabalho utilizou-se revisão bibliografia, SIG (Arcgis 9.3), bases cartográficas, imagens dos satélites, Spot- 5 do ano de 2008, Landsat-5 dos anos 2008 e 2010, ResourceSat-1 do ano 2012 e Landsat-8 dos anos 2013, 2014 e 2015, mapas digitais, imagens Shuttle Radar Topographic Mission (SRTM), obtidas por sensoriamento remoto e técnicas de geoprocessamento na produção de informações sobre a expansão agrícola.

Para obtenção das áreas de expansão agrícola do município, foram realizadas classificações de imagens dos sensores TM-Landsat-5, LISSResourceSat-1 e OLI-Landasat-8, com resolução espacial de $30 \mathrm{~m}, 24 \mathrm{~m}$ e $15 \mathrm{~m}$, respectivamente. O método de classificação utilizado foi MAXVER (Máxima Verossimilhança) e as classes encontradas foram: (1) Agricultura, (2) Floresta, (3) Pastagem, (4) Espelho d' água e (5) Solo exposto.

Para a classificação supervisionada, foram coletadas no mínimo 20 , amostras para cada classe, o que possibilitou realizar uma análise quantitativa das áreas em expansão e um diagnóstico dos diferentes tipos de usos do solo. Após, foram realizadas aferições de campo para identificar os espaços de expansão agrícolas, e coletadas as coordenadas dos pontos de controle, esses pontos foram plotados na imagem para a caracterização das classes temáticas para posterior classificação. A manipulação das imagens envolveu operações de processamento digital, em que foram realizadas: classificações, cruzamentos e análises espaciais, visando à criação de mapas das áreas agrícolas.

Para o armazenamento dos dados referentes aos diversos aspectos abordados, foi gerado, a partir dos recursos disponíveis no SIG, um banco de dados georreferenciado permitindo desta forma a associação dos dados estudados aos atributos geográficos dos mapas temáticos produzidos. A técnica utilizada para reunir, organizar e cruzar as informações geradas pelos diversos estudos (estudos disponíveis e desenvolvidos) constituiu o banco de dados georreferenciado, o qual possibilitou a manipulação das informações sobre a área, em meio digital, permitindo a atualização permanente e sistemática das informações constantes no presente trabalho.

O mosaico de imagem SRTM foi utilizado como base de dado da altitude e a classificação da declividade adotada como referência foi a da Embrapa (1999), sendo Plano, de 0 a 3\%; Suave ondulado, de 3 a $8 \%$; Ondulado, de 8 a $20 \%$ e Forte ondulado, de 20 a $45 \%$. Nesta etapa, foram utilizadas as ferramentas Slope para geração do Modelo Digital de Elevação (MDE) e Reclassify para geração das classes de declividade. A classificação supervisionada foi produzida através da seleção de amostras de treinamento, referentes a cada classe de uso, baseando-se em chaves de interpretação (Figura 2).

AGRARIAN ACADEMY, Centro Científico Conhecer - Goiânia, v.5, n.9; p. 3802018 


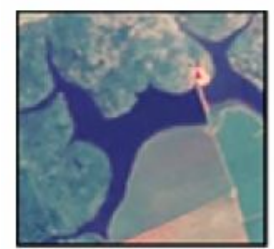

Água: Cor azul ou preta.

textura lisa, forma

regular/irregular.

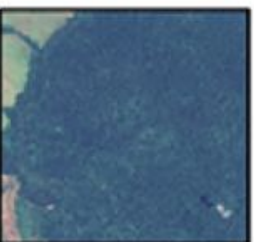
Florestas: Cor verde escuro,
textura rugosa, com
$\rightarrow$ predominio de vegetação
ombrófila aberta e densa,
floresta estacional e
cerrado.

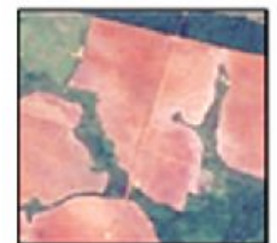

Solo exposto: Cor magenta tendendo ao branco,

textura lisa, forma regular, junto a áreas urbanas ou agricolas.
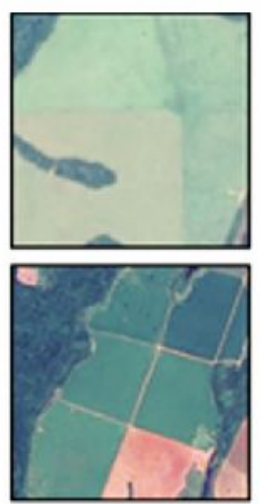

Pastagens: Predominantemente formada por gramíneas e pequenos arbustos esparsos, apresenta-se na imagem com tons claros devido à alta refletåncia do solo, variando de tons de verde claro a verdeamarelado.

Agricultura: Cor magenta (solo preparado), verde claro (cultura em estagio inicial) e verde escuro (cultura em estagio adulto), textura lisa, forma geométrica, talhões.

FIGURA 2 - Chaves para identificação das classes temáticas de cobertura dos solos. Alta Floresta-MT, (2015). Fonte: Os autores

Foi aplicada às imagens do sensor OLI-Landsat-8, e a fusão das bandas coloridas com a banda pancromática possibilitou resolução espacial de $15 \mathrm{~m}$. Baseado na classificação preliminar foi realizado o reconhecimento das áreas de expansão agrícola identificadas com o objetivo de confirmar a fidelidade das informações, bem como a coleta de pontos, com GPS, para posterior correção geométrica (georreferenciamento) da imagem. Os pontos foram coletados e plotados na imagem buscando identificar as áreas agrícolas em expansão (Figura 3).

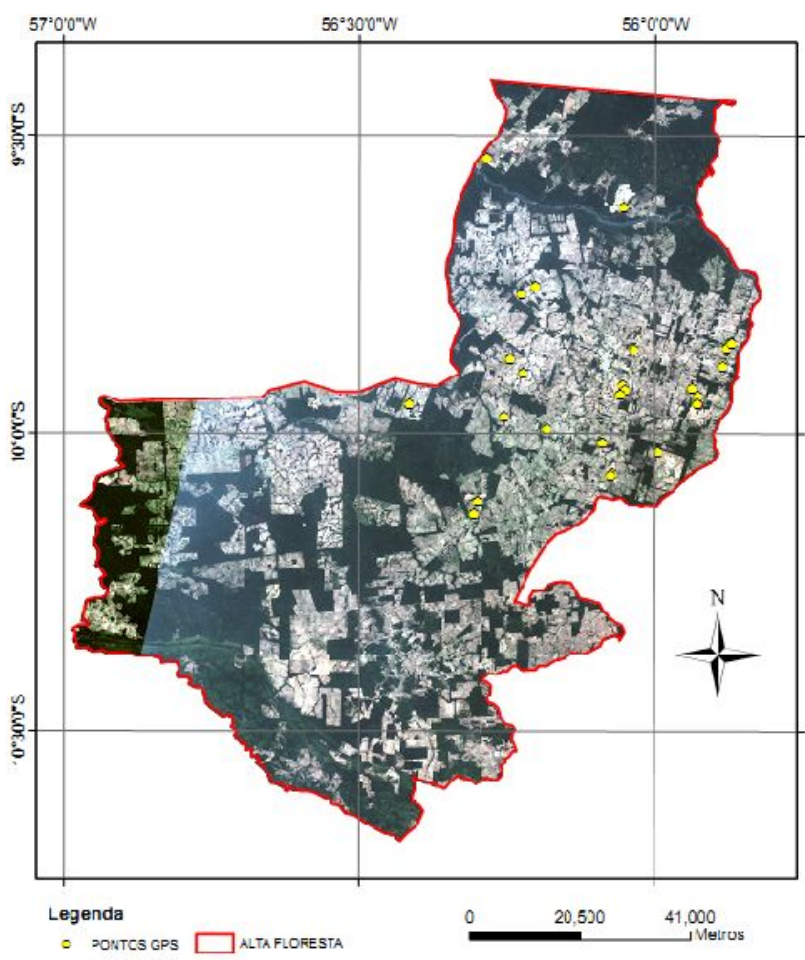

FIGURA 3 - Localização e distribuição dos pontos coletados com GPS. Alta FlorestaMT, (2015). Fonte: Os autores

AGRARIAN ACADEMY, Centro Científico Conhecer - Goiânia, v.5, n.9; p. 3812018 


\section{RESULTADOS E DISCUSSÃO}

Quando avalia-se a expansão agrícola em escala temporal no Município de Alta Floresta-MT, duas variáveis são observadas, sendo uma o uso da agricultura como meio de recuperar áreas degradadas onde havia pastagens, barateando custos da chamada "reforma das pastagens", nesta variável, o produtor faz apenas uma safra com uma cultura comercial e depois retorna com a pastagem na área. E a outra é um contínuo uso da área com lavouras ao longo dos anos.

Lorensini et al. (2015), em trabalhos realizados na região do MATOPIBA mostraram que a grande parte da expansão agrícola ocorreu principalmente em áreas já antropizadas. Carneiro-Filho e Costa (2016) apontam que as conversões de áreas ocupadas com pastagem para produção de grãos intensificam a produtividade em uma mesma área, o que traz à tona uma oportunidade estratégica para o agronegócio, que poderá expandir a produção de grãos em áreas que já foram ocupadas por pastagens, sem a necessidade de novos desmatamentos.

Dentro deste contexto, Cordeiro et al. (2015) também ressaltam que os sistemas em integração podem ser mais lucrativos por causa da diversificação das atividades econômicas, da redução de custos e dos aumentos de produtividade e especialmente no sistema de rotação lavoura-pasto, há aumento de produtividade de grãos cultivados após a pastagem, que também produz mais após o solo ter sido utilizado para cultivo de grãos. Essa pastagem mais produtiva resultará em maior ganho de peso de bovinos ou produção leiteira, reduzindo os riscos de degradação e evitando desmatamentos.

Observa-se que, ao longo do período 2008 a 2015, houve queda de $1,46 \%$ da área de floresta, passando de 56,25\% em 2008 para $54,79 \%$ em 2015. Isto corresponde a área de 13.014 ha em oito anos, com área de desmatamento média de 1.626 ha/ano. Análises feitas por Romão (2014), no município de Santa Rita de Cássia-BA, mostraram também redução na vegetação ao longo dos anos, onde, no ano de 1988, a Floresta ocupava $88 \%$ da área do município, reduzindo para $81 \%$ em 2008.

Os resultados mostram que as florestas foram convertidas principalmente em pastagens, passando de $32,59 \%$ no ano de 2008 para $33,85 \%$ em 2015 . O solo exposto diminuiu de 9,81\% em 2008 para 9,15\% em 2015 (Figura 4). Lembrando que esse resultado pode ter sofrido influência porque as imagens do ano 2008 do sensor TM-Landsat-5 são da estação de estiagem e as imagens do ano 2015 do sensor OLI-Landsat-8 são da estação chuvosa.

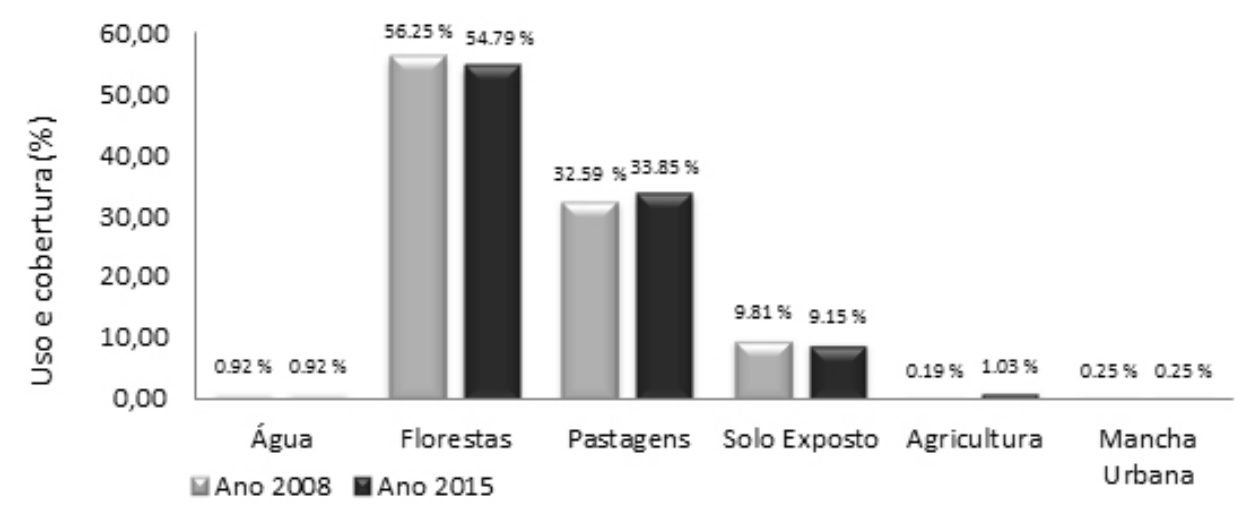

FIGURA 4 - Gráfico comparativo das classes de uso e ocupação da Terra nos anos de 2008 e 2015 no município de Alta Floresta-MT. Alta Floresta-MT, (2015). 
Poucas áreas de agricultura são observadas, correspondendo, no ano de 2008, apenas a $0,19 \%$ da área total, sendo parte dessas áreas agrícolas concentradas ao norte do município nas proximidades do Rio Teles Pires (Figura 5). Esse cenário muda e a agricultura passa a representar $1,03 \%$ da área total do Município de Alta Floresta em 2015, com as áreas agrícolas se concentrando nas margens da rodovia MT-208 (Figura 6).

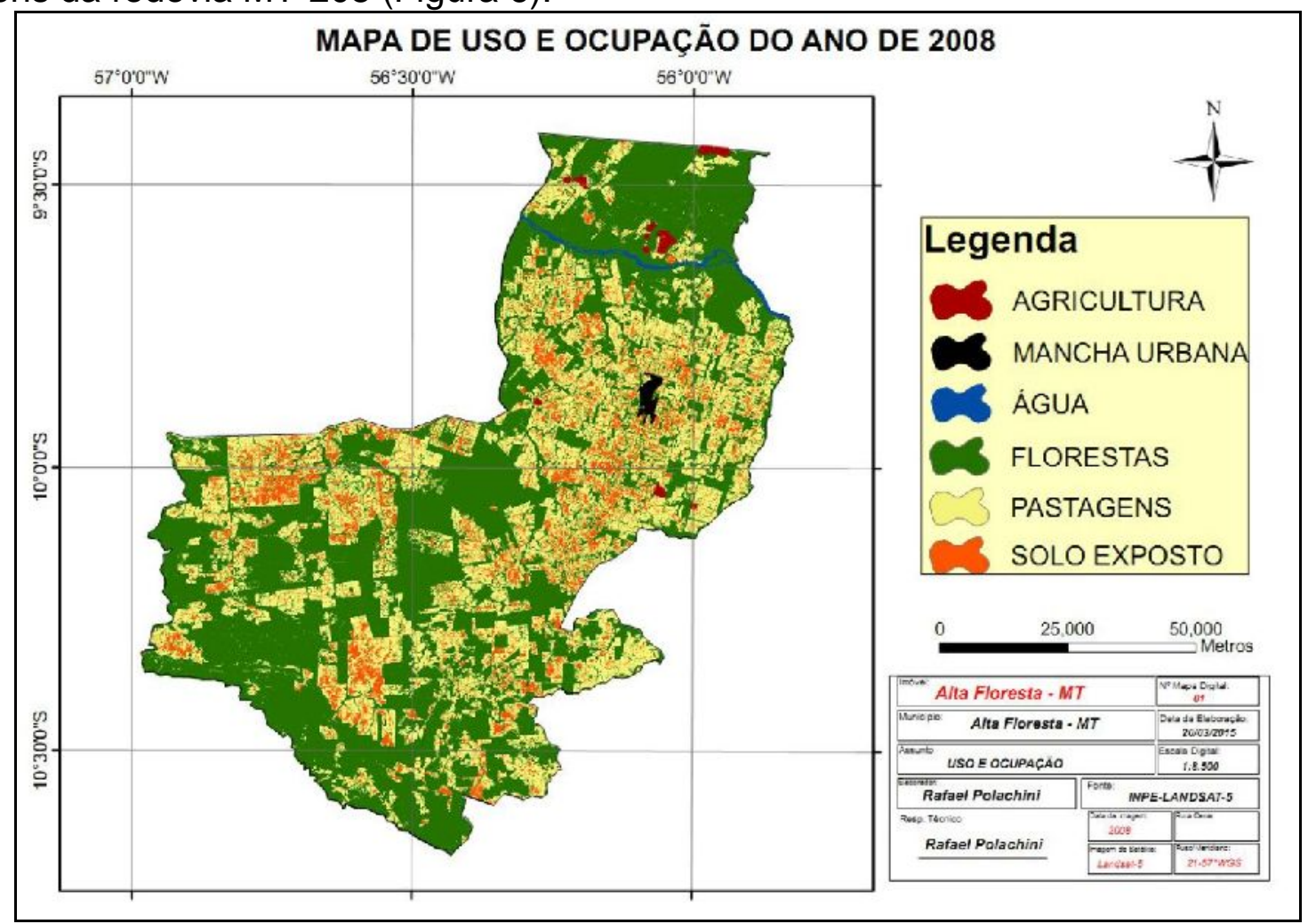

FIGURA 5 - Uso e ocupação do município de Alta Floresta-MT para o ano de 2008. Alta Floresta-MT, (2015).

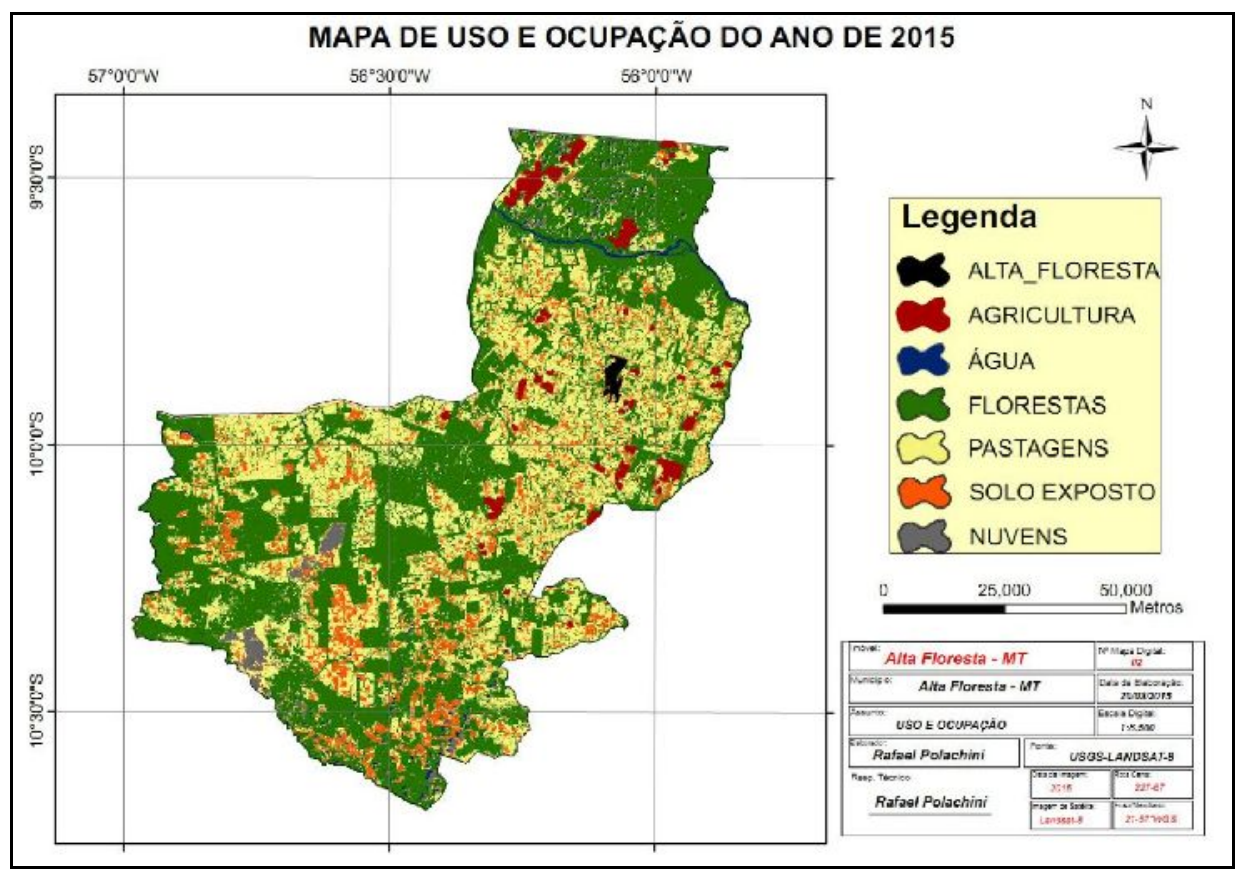

FIGURA 6 - Uso e ocupação do município de Alta Floresta-MT para o ano de 2015. Alta Floresta-MT, (2015).

AGRARIAN ACADEMY, Centro Científico Conhecer - Goiânia, v.5, n.9; p. 3832018 


\section{Expansão agrícola}

A evolução agrícola entre os anos de 2008 e 2015 pode ser observada na Figura 7. No decorrer da classificação, diversos erros relacionados ao classificador MAXVER do Arcgis 9.3 foram observados, ocorrendo confusão entre classes, não sendo possível distinguir áreas de solo exposto para agricultura, por exemplo, de um solo revolvido para reforma de pastagem. Nesse caso, houve a necessidade de uma vetorização manual de cada área onde se desenvolveu a agricultura no período avaliado e, por meio de visitas a campo através de pontos georeferrenciados, confirmou-se agricultura.

EXPANSÃO AGRÍCOLA DOS ANOS DE 2008 - 2015

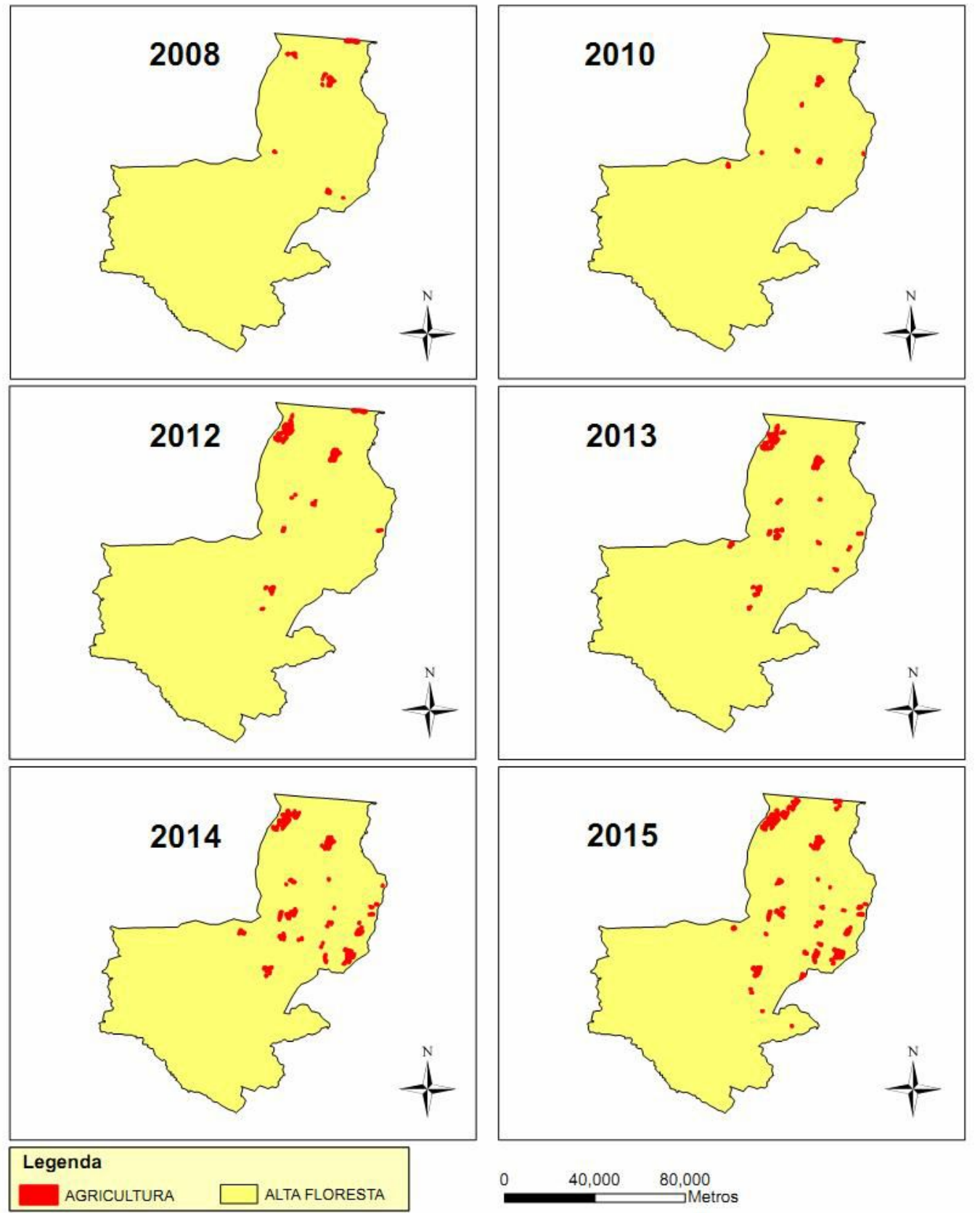

FIGURA 7 - Expansão agrícola no município de Alta Floresta-MT em escala multitemporal nos anos de 2008 a 2015. Alta Floresta-MT, (2015). 
A série temporal dos oito anos avaliados ilustrando a expansão agrícola pode ser visualizada na Figura 8.

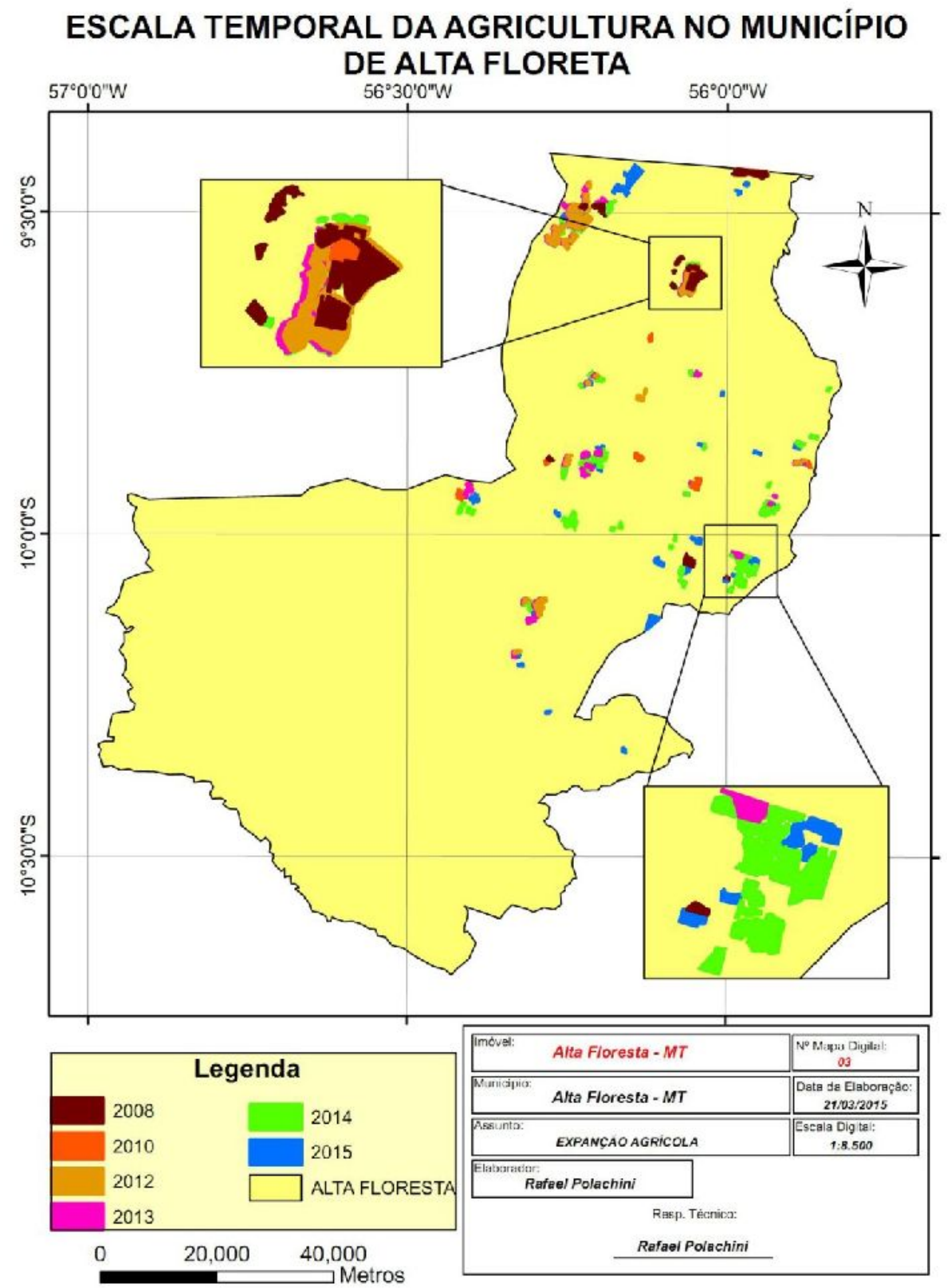

FIGURA 8 - Destaque da expansão agrícola em duas propriedades distintas do município de Alta Floresta-MT nos anos de 2008 a 2015. Alta Floresta-MT, 2015.

Através das informações obtidas por meio de interpretação visual e cálculos de área, o município de Alta Floresta apresentava área cultivada de 1.665 ha em 2008, porém, essa área diminuiu no ano de 2010, para 1.185 ha, isso ocorreu devido a fatores edafoclimáticos. Nos anos subsequentes, a área cultivada tendeu a aumentar, chegando a 9.183 ha no ano de 2015, contudo, essa área corresponde a apenas $1,03 \%$ da área total do município (Figura 9). 


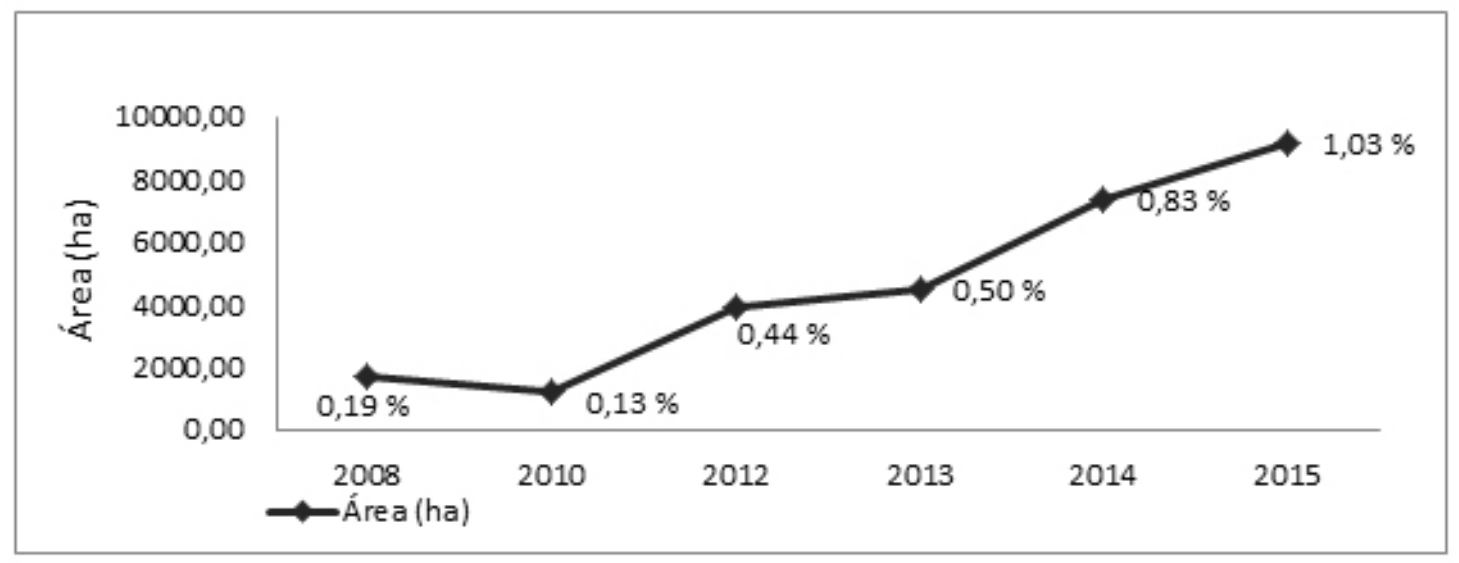

FIGURA 9 - Gráfico referente à área agrícola e respectivas porcentagens do município de Alta Floresta, MT nos anos de 2008 a 2015. Alta Floresta-MT, (2015).

Em trabalho similar realizado por Santos (2012), realizado em uma série de 1984 a 2006 no munícipio de Luís Eduardo Magalhães-BA, mostrou, que no ano de 2006, o município apresentava área cultivada de 218.667,6 ha e que correspondia a mais da metade da área municipal $(54,46 \%)$. Entre os principais cultivos em ordem econômica, destacavam-se soja, milho e algodão.

Delmon et al. (2013), em estudos realizados sobre a expansão da agricultura em Sorriso/MT de 1988 a 2008, mostraram que 67,44\% da área do município foi incorporada à monocultura, restando atualmente apenas 32,52\% (300.551,5 ha) da vegetação original do município.

Freitas e Mendonça (2016) mostram que, a expansão agrícola brasileira, está bem definida na rota Centro Noroeste de ocupação de novos espaços. Neste movimento ressaltam-se trechos ocidentais da região Norte em associação com mesorregiões oriental do Tocantins, sul maranhense e extremo oeste baiano e a ocupação de novas áreas no segmento sul da região Norte, em zonas de transição que estão centradas nas mesorregiões do norte e nordeste mato-grossenses.

Conforme Souza (2016), o avanço da fronteira agrícola no estado de Mato Grosso encontra-se em estágios distintos, revelando espaços estruturados diferenciados, ocorrendo à existência de fronteiras consolidadas altamente tecnificadas, inclusive com a presença de grandes agroindústrias, fase mais avançada do agronegócio, e acima desta fronteira, está a presença da pecuária que vai abrindo novos territórios para o agronegócio.

\section{Relevo e declividade}

Predominam, na área de estudo, terras com baixa declividade e esta característica favorece a implantação do agronegócio, podendo indicar solos de menor susceptibilidade à erosão e maior viabilidade de mecanização. No entanto, para definir a aptidão agrícola, outros fatores limitantes devem ser considerados, como: excesso de água, pedregosidade, rochosidade, fertilidade natural, clima e outros atributos do solo.

No município de Alta Floresta, mais de $90 \%$ da área está entre 0 e $8 \%$ de declividade, sendo o relevo considerado plano a suave ondulado, as demais áreas estão nas classes ondulado e forte ondulado (Tabela 1), essas duas últimas classes estão presentes nos extremos do município ao norte, próximas ao Rio Teles Pires, e, 
ao sul, é constituída pela Serra dos Apiacás. Domingues (2012), em estudos realizados na microbacia Mariana no município de Alta Floresta-MT, também constatou que o relevo predominante é plano e suave ondulado em $96,21 \%$ da área avaliada.

TABELA 1 - Extensão e distribuição percentual das formas de relevo do município de Alta Floresta, MT. Alta Floresta-MT, 2015.

\begin{tabular}{ccc}
\hline Declividade & Área (ha) & $\%$ \\
\hline 0-3 \% (plano) & $465.954,93$ & 52,29 \\
$3,01-8 \%$ (suave ondulado) & $367.784,55$ & 41,26 \\
$8,01-20 \%$ (ondulado) & $55.540,08$ & 6,23 \\
$20,01-45 \%$ (forte ondulado) & $1.832,22$ & 0,22 \\
\hline
\end{tabular}

Ao sobrepor a máscara criada pela extensão dos cultivos agrícolas de 2008 a 2015, pode-se afirmar que toda a extensão agrícola estabeleceu-se sobre terrenos com declividade entre 0 e $8 \%$. Trevisan e Moschini (2015) em suas avaliações no município de Americana SP, constataram que 96,3\% da área apresentou condições favoráveis tanto para habitação urbana quanto para a prática de agricultura intensiva com o auxílio de maquinário, devido à característica da área de possuir relevos planos e/ou com suaves ondulações. Do mesmo modo Santos (2012), em estudos realizados no município de Luís Eduardo Magalhães-BA, verificou que a declividade do terreno variou de $0 \%$ a $12 \%$, com valores médios de 4,20\%.

$\mathrm{Na}$ avalição do Modelo Digital de Elevação (MDE) da área de estudo, foi constatado que a altitude em relação ao nível médio dos mares, varia de 200 a 480 m (Figura 10), tendo a Serra dos Apiacás com altitudes mais elevadas e decaindo à medida que se aproxima do Rio Teles Pires ao norte e Rio Apiacás a oeste. Quando são comparados o mapa de uso e ocupação com o mapa de elevação, nota-se que há pouco predomínio de áreas antropizadas em altitudes acima de $400 \mathrm{~m}$.

MAPA DE RELEVO

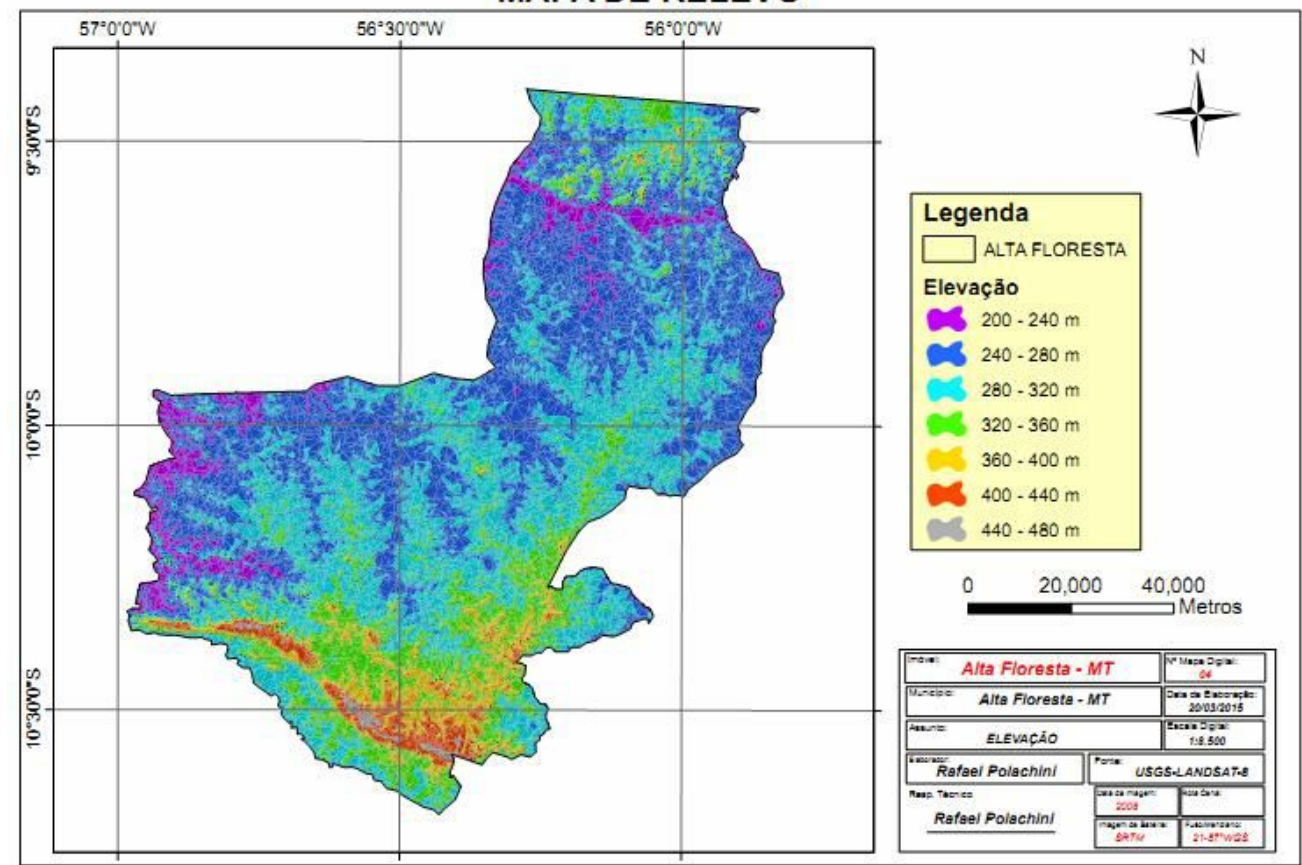

FIGURA 10 - Modelo Digital de Elevação do município de Alta Floresta, MT. Alta Floresta-MT, (2015).

AGRARIAN ACADEMY, Centro Científico Conhecer - Goiânia, v.5, n.9; p. 3872018 


\section{CONCLUSÃO}

O uso e ocupação da terra no Município de Alta Floresta-MT são intensos. No período avaliado, houve evolução da área desmatada em 1,46\%, tendo pastagens ocupando essas novas áreas, reforçando o ciclo de substituição da floresta por pasto na Amazônia.

A prática da agricultura evoluiu em 2008, a atividade ocupava $0,19 \%$ da área municipal, chegando a 1,03\% no ano de 2015 e o crescimento nos últimos anos ainda é pouco expressivo em relação na área total do município, onde a principal atividade é a criação de gado de corte, observa-se também que em 2015 o município possuía $33,85 \%$ do solo com pastagem em diferentes níveis de produtividade.

As análises multitemporais realizadas possibilitaram identificar e monitorar os monocultivos agrícolas e as atividades agropecuárias com grande facilidade e agilidade no Município de Alta Floresta-MT, possibilitando ser replicadas para outros municípios.

\section{REFERÊNCIAS}

BARBOSA, M. Z. Fronteira Agrícola: a Soja na Amazônia Legal. Instituto de Economia Agrícola - IEA. Análises e Indicadores do Agronegócio, São Paulo, v. 10, n. 1, p. 5. 2015.

CARNEIRO FILHO, A; COSTA, K. A expansão da soja no Cerrado: Caminhos para a ocupação territorial, uso do solo e produção sustentável. São Paulo, $p$. 28. 2016.

CORDEIRO, L. A. M; VILELA, L; MARCHÃO, R. L; KLUTHCOUSKI, J; MARTHA JÚNIOR, G. B. Integração Lavoura-Pecuária e Integração Lavoura-PecuáriaFloresta: Estratégias para Intensificação Sustentável do Uso do Solo. Cadernos de Ciência e Tecnologia, Brasília, v. 32, n. 1/2, p. 15-43. 2015.

CRISPIM, L. C; ALBANO, A. O uso das imagens de satélite como recurso didático no ensino de geografia. Pesquisar - Revista de Estudos e Pesquisas em Ensino de Geografia, Florianópolis, v. 3, n. 4, p. 46-57. 2016.

DELMON, J. M. G; SOARES, E. R. C; KREITLOW, J. P; NEVES, R. J; NEVES, S. M. A. S. Expansão da agricultura em Sorriso/MT de 1988 a 2008. Revista Enciclopédia Biosfera, Goiânia, v.9. n 16. p. 1173-1187. 2013.

DOMINGUES, T. R. Geotecnologia aplicada ao mapeamento pedológico detalhado da microbacia Mariana, município de Alta Floresta - MT. 2012. 25p. Trabalho de Conclusão de Curso (Graduação em Agronomia) - Faculdade de Ciências Agrárias e Biológica, Universidade do Estado de Mato Grosso, Alta Floresta, 2012.

EMBRAPA, Sistema Brasileiro de Classificação de Solos, Brasília, 166p. 1999.

FERREIRA, J. C. V. Mato Grosso e Seus Municípios. Cuiabá: Secretaria de Estado de Educação, Editora Buriti, 1ª ed. 660p. 2001. 
FREITAS, R. E; MENDONÇA, M. A. A. Expansão Agrícola no Brasil e a Participação da Soja: 20 anos. Revista de Economia e Sociologia Rural, Piracicaba, v 54, n. 3 , p. 497-516. 2016.

LOPES, S. M. F; CABRAL, J. B. P; BRAGA, C. C; RAMALHO, F. L. Avaliação Espaço-Temporal do uso da Terra nas Bacias Hidrográficas do Ribeirão Paraíso-Go e Córrego Cerrado/Cadunga-Mg. Revista Eletrônica do Curso de Geografia UFG/REJ, Jataí, n. 27, p. 114-133. 2016.

LORENSINI, C. L; VICTORIA, D. C; VICENTE, L. E; MAÇORANO, R. P. Mapeamento e identificação da época de desmatamento das áreas de expansão da agricultura no MATOPIBA. In: Simpósio Brasileiro de Sensoriamento Remoto, 17. Anais... Instituto Nacional de Pesquisas Espaciais, João Pessoa, p. 3542-3548. 2015.

PINTO, D. X; ESQUERDO, J. C. D. M; COUTINHO, A. C. Mapeamento da expansão agrícola no estado do Mato Grosso em 11 anos a partir de técnica baseada em séries temporais de imagens de NDVI. In: Simpósio Brasileiro de Sensoriamento Remoto, 16. Anais... Instituto Nacional de Pesquisas Espaciais, Foz do Iguaçu, p. 201-206. 2013.

ROMÃO, G. O. Uso de geotecnologias para a análise da dinâmica do uso da Terra no município de Santa Rita de Cássia (BA). 2014. 58p. Dissertação (Mestrado em Gestão Ambiental e Territorial). Universidade de Brasília. Brasília. 2014.

SANTOS, P. S; Expansão agrícola de 1984 a 2006 e Estimativas agrícolas por sensoriamento Remoto e SIG no munícipio de Luís Eduardo Magalhães-BA. 2012. 106p. Dissertação (Mestrado em Sensoriamento Remoto) - Instituto Nacional de Pesquisas Espaciais, São José dos Campos, 2012.

SEPLAN. Secretaria de Estado de Planejamento e Coordenação Geral. Unidades Climáticas do Estado de Mato Grosso. Zoneamento Sócio Econômico Ecológico. Atlas Climatológico de Mato Grosso - Universidade Federal do Estado de Mato Grosso, Cuiabá, 2006. CD-ROM.

SOUZA, R. Infraestruturas de Logística e Transporte em Mato Grosso: Uma leitura geográfica. 2016. 131p. Dissertação (Mestrado em Geografia). Programa de Pós-Graduação em Geografia, Universidade Federal de Mato Grosso. Rondonópolis, 2016.

TREVISAN, D. P; MOSCHINI, L. E. Dinâmica de Uso e Cobertura da Terra em Paisagem no Interior do Estado de São Paulo: Subsídios para o Planejamento. Fronteiras: Journal of Social, Technological and Environmental Science. São Carlos, v.4, n.3, p. 16-30. 2015.

VIEIRA FILHO, J. E. R. Expansão da Fronteira Agrícola no Brasil: Desafios e Perspectivas. Instituto de Pesquisa Econômica Aplicada - IPEA. Rio de Janeiro, p. 28. 2016. 